MATEC Web of Conferences 3, 01054 (2013)

DOI: $10.1051 /$ matecconf/20130301054

(c) Owned by the authors, published by EDP Sciences, 2013

\title{
A thermodynamic analysis of the Ge-Ru system
}

\author{
K. Mahdouk, A. Iddaoudi, M. Ait Amar, and N. Selhaoui \\ Laboratoire de Thermodynamique et Energétique, Faculté des Sciences, Université Ibn Zohr, Agadir, Maroc
}

The experimental phase equilibria of the Ge-Ru system was first determined by Raub and Fritzsche [1] who reported the existence of two intermediate phases: GeRu which formed congruently at $1470^{\circ} \mathrm{C}$ and $\mathrm{Ge}_{3} \mathrm{Ru}_{2}$ which formed by a peritectic reaction at $1452^{\circ} \mathrm{C}$. Later, Perring et al. [2] reinvestigated the phase relationship of this system by means of differential thermal analysis (DTA), X-ray diffraction (XRD) and electron probe microanalyses (EPMA). They found that $\mathrm{GeRu}$ and $\mathrm{Ge}_{3} \mathrm{Ru}_{2}$ melted congruently at $1510^{\circ} \mathrm{C}$ and $1551^{\circ} \mathrm{C}$ respectively.

The first optimization of the Ge-Ru system was performed by Charles et al. [3] on the basis of the experimental results of Perring et al. [2]. They noted a problem concerning the calculated temperature of the eutectic $\mathrm{L} \leftrightarrow \mathrm{GeRu}+\beta \mathrm{Ge}_{3} \mathrm{Ru}_{2}$ equilibrium which differs from experiment by about $20^{\circ} \mathrm{C}$ equal to the melting point of $\mathrm{GeRu}\left(1508^{\circ} \mathrm{C}\right)$. Most recently, Long et al. [4] performed an assessment of the Ge-Ru system using the mixing enthalpies of the liquid calculated from the Miedema's empirical model [5] in spite of the fact that a factor of 4 could be noted between the experimental enthalpy of formation and the Miedema's model predicted one for the $\mathrm{Ge}_{3} \mathrm{Ru}_{2}$ phase. These authors adopted the peritectic reaction $\mathrm{L}+\beta \mathrm{Ge}_{3} \mathrm{Ru}_{2} \leftrightarrow \mathrm{GeRu}$ instead of the eutectic equilibrium reported more recently by [2] and mentioned that further studies on this reaction are necessary.

In light of these results, we have reassessed the thermodynamic parameters of the Ge-Ru system to take into account the recent experimental data determined by [2-6]. Particular attention was accorded to the controversial equilibrium involving the liquid, $\beta \mathrm{Ge}_{3} \mathrm{Ru}_{2}$ and $\mathrm{GeRu}$ phases. This work first provides a critical review of the experimental phase equilibrium and thermodynamic data available in the literature, then presents the thermodynamic models used, and discusses the results obtained.

\section{References}

1. E. Raub, W. Fritzsche, Z. Matallkd. 53779 (1962)

2. L. Perring, P. Feschotte, J.C. Gachon, J. Phase Equilibria 17(2) 101 (1996)

3. J.C. Charles, L. Perring, J.C. Gachon, J. Phase Equilibria 19(5) 449 (1998)
4. Z.H. Long, H.S. Liu, Z.P. Jin, J. Alloys Compd. 479 262 (2009)

5. F.R. de Boer, R. Boom, W.C.M. Mattens, A.R. Miedema, A.K. Niessen, Cohesion in Transition Metals alloys, North-Holland Physics Publishing, Amsterdam, (1988)

6. L. Perring, J.C. Gachon, J. Alloys Compd. 224228 (1995) 